\title{
AS RELAÇÕES INTERPESSOAIS NA SALA DE AULA E A BRINQUEDOTECA ESCOLAR
}

Deise Caroline Rodrigues da Silva, Andréia Cristiane Silva Wiezzel

UNESP - Campus de Presidente Prudente - Faculdade de Ciências e Tecnologia - Pedagogia. deise.karolzinha2008@yahoo.com.br Núcleo de Ensino

\section{RESUMO}

Este trabalho vem apresentar o resultado parcial de um projeto de extensão e pesquisa denominado Contribuições às Relações Interpessoais e à Dinâmica de Sala de Aula, realizado por alunos e docentes da FCT-UNESP em Presidente Prudente. $O$ projeto em questão estuda as relações interpessoais entre crianças que freqüentam a educação infantil em uma escola pública do município. Aspectos relacionados à timidez excessiva e à agressividade são investigados pelos pesquisadores, que acompanham as crianças em atividades lúdicas na brinquedoteca da escola. O projeto busca, além de investigar a agressividade e a timidez, fornecer subsídios aos professores e pais sobre como lidar com os conflitos infantis e, também, ajudar os alunos a se relacionarem melhor dentro do ambiente escolar.

Palavras-chave: brinquedoteca escolar, relações interpessoais, sala de aula.

\section{THE INTERPERSONAL RELATIONSHIPS IN THE CLASSROOM AND TOY SCHOOL}

\section{ABSTRACT}

This work comes to present the partial results of a research and extension project called Interpersonal Relations and Contributions at the Dynamic Classroom, conducted by students and teachers in the FCTUNESP at Presidente Prudente - São Paulo. The project involved studying interpersonal relationships among children attending kindergarten in a public school in the county. Aspects related to excessive timidity and aggression are investigated by researchers, who accompany the children in toy/play activities in school. The project seeks also to investigate the aggressiveness and shyness, to provide grants to teachers and parents on how they deal with childrens conflicts and also help children relate better within the school environment.

Keywords: toy school, interpersonal relationships, classroom. 


\section{INTRODUÇÃO E JUSTIFICATIVA}

Este trabalho apresenta resultados parciais obtidos no Projeto Contribuições às Relações Interpessoais e à Dinâmica de Sala de Aula ainda em andamento, no qual crianças que apresentam dificuldades no âmbito sócio-afetivo são acompanhadas por estudantes do curso de Pedagogia da FCT / UNESP. As crianças participantes do projeto encontram-se matriculadas no ensino infantil e fundamental em duas escolas públicas de Presidente Prudente, selecionadas por apresentar atitudes agressivas em sala de aula ou timidez excessiva.

As relações criadas dentro da escola bem como as familiares fazem parte do desenvolvimento afetivo das crianças e este por sua vez, influencia o processo de ensinoaprendizagem. Dessa forma o convívio escolar é muito importante para o desenvolvimento da sociabilidade infantil, mas, nem sempre esse processo ocorre de forma tranqüila. É freqüente os professores se queixarem de que suas crianças apresentam algumas características que interferem em seu processo de aprendizagem e, por vezes, dos colegas também. É mencionada pelos professores a agressividade excessiva, em que a criança agride os colegas fisicamente ou verbalmente. Também a timidez excessiva ou a apatia, em que a criança se isola e não interage com os demais. Esses problemas exigem um tratamento diferenciado por parte dos professores que, na maioria das vezes, se vêem em situação difícil por não terem formação suficiente para realizar esse tipo de intervenção.

Segundo estudos realizados por Winnicott (1997) as atitudes dessas crianças estão comumente ligadas a conflitos internos, podendo haver grande influência das relações que foram estabelecidas durante os primeiros anos de vida das crianças com suas mães. Nessa fase, é muito importante que se estabeleça entre esses dois indivíduos uma relação de apego seguro que contribuirá para uma menor existência de problemas cognitivos e sócio-emocionais no período escolar.

O apego seguro construído durante a infância proporcionará a criança a ter mais segurança, maior auto-estima e autonomia, contribuindo para a formação de relações afetivas mais estáveis com indivíduos e com grupos. Winnicott (1997) aponta a estrutura familiar, em especial o relacionamento mãe/filho, tendo um grande papel na organização da personalidade da criança. Fatores como calor, proteção, afeto e conforto, alem dos cuidados físicos, também são essenciais como referência ao longo da vida, para a construção de futuras relações.

Porém, muitas vezes, a criança acaba não tendo o suporte necessário para o seu desenvolvimento emocional ou físico, podendo ter dificuldades para lidar com sentimentos e emoções. Tal dinâmica pode resultar em características relacionadas à timidez, apatia, agressividade e outros. Os pais e professores, em sua maioria, acabam não compreendendo o que essas crianças precisam e se desgastam muito, não obtendo resultado satisfatório.

Nessa perspectiva procurou-se, por meio do projeto, investigar, à luz da psicanálise winnicottiana e por meio do lúdico, as possíveis causas dos conflitos dessas crianças e também trabalhar com os professores e pais para que estes tomem consciência das necessidades destas e possam ajudá-las.

\section{OBJETIVOS}

- identificar os conflitos existentes entre os alunos/professores e alunos/alunos dentro da sala de aula como, também, a natureza destes conflitos;

- promover possibilidades de expressão de conflitos às crianças, através do brincar; 
- sensibilizar os pais e professores acerca das necessidades afetivas dessas crianças como também orientá-los em como lidar com elas;

- possibilitar ao aluno do curso de Pedagogia a aproximação com a realidade escolar;

- contribuir na formação continuada dos docentes nos aspectos da sensibilização, conscientização e reflexão sobre as necessidades sócio-afetivas das crianças.

\section{METODOLOGIA}

O projeto se baseia na pesquisa-ação, tendo como referência principal o psicanalista infantil D. W. Winnicott e ainda outros autores que estudam o desenvolvimento sócio-afetivo infantil no âmbito educacional e social familiar.

Quinzenalmente são realizadas reuniões com a coordenadora e textos específicos são discutidos pelo grupo. São oferecidas orientações individuais e coletivas com respeito aos encontros lúdicos com as crianças, aplicação de questionários e entrevistas realizadas com os professores e responsáveis pelas crianças para a obtenção de dados.

Uma vez por semana são realizados encontros lúdicos com as crianças, individualmente, por aproximadamente 40 minutos, nos quais brincam do modo e com o que Ihes aprouver na brinquedoteca escolar.

A escolha pelo brincar justifica-se por ser uma atividade do cotidiano da criança, sendo o meio pelo qual ela expressa medos, angústias e outros sentimentos:

Ao brincar, a criança desloca para o exterior seus medos, angústias e problemas internos, dominando-os por meio da ação. Repete no brinquedo todas as situações excessivas para seu ego fraco e isto lhe permite, devido ao domínio sobre os objetos externos a seu alcance, tornar ativo aquilo que sofreu passivamente, modificar um final que the foi penoso, tolerar papéis e situações que seriam proibidas na vida real tanto interna como externamente e também repetir à vontade situações prazerosas." (ABERASTURY, 1992, p. 15)

Winnicott (2005) afirma, ainda, que a atividade lúdica além de possibilitar a expressão e elaboração de conflitos resulta em efeito terapêutico sem uma atividade terapêutica em sentido estrito. A atenção e disponibilidade do pesquisador enquanto acompanha as brincadeiras das crianças favorecem o efeito terapêutico. Com isso o autor amplia a concepção sobre o brincar e os seus benefícios sobre as crianças e aproxima a educação (em sua dimensão lúdica) da psicanálise.

Desta forma, o brincar pode ser utilizado no cotidiano da educação infantil sem que o professor seja visto como terapeuta, pois esta não é sua função. Ainda assim, o educador pode se utilizar de conhecimentos advindos da psicanálise para melhor compreender 0 desenvolvimento emocional de seus alunos e assim poder auxilia-los de maneira mais efetiva em suas expressões agressivas.

São realizadas pelos pesquisadores, como forma de coleta de dados, entrevistas com os professores das crianças e com seus pais ou responsáveis. As atividades desenvolvidas são lançadas em um site, associado a aplicativo web e a coordenadora do projeto tem acesso as informações para subsidiar os direcionamentos práticos e teóricos.

\section{RESULTADOS E DISCUSSÃO}

Uma das crianças com as quais trabalho é um garoto de quatro anos - 'Marthin'(nome fictício) - aluno do Pré I que freqüenta a instituição em período Integral. Ele participa do projeto pelo 
fato de possuir, na concepção da professora, características agressivas em sala de aula.

Os encontros foram iniciados em março do presente ano e duram, aproximadamente, 50 minutos. As duas primeiras vezes em que tive contato com a referida criança, fora em sala de aula. Presenciei momentos de fúria, nos quais mostrou os punhos, disse que iria bater e, de fato, acabou se atracando com uma das outras crianças, levando a professora a ter que intervir de forma muito. A frase: "Eu vou bater", foi repetida por ele diversas vezes.

No primeiro dia de brincadeira na brinquedoteca, ele se mostrou muito curioso, e ficou muito tempo ocupado brincando de montar torres e olhando curiosamente para dentro de objetos com furos e cavidades. Aqui, com bases nas teorias estudadas, observa-se elementos de conflitos que envolvem a sexualidade, podendo a curiosidade pelos objetos com orifícios representar, hipoteticamente, o desejo de volta ao útero materno, conforme Aberastury (1992).

Uma de suas brincadeiras preferidas no começo, além das peças de montar, eram as peças de encaixe e, em um dos encontros, ele tentou durante algum tempo encaixar três peças e quando conseguiu, jogou-as com impaciência na caixa e começou a chorar, pedindo pela mãe. Em seguida disse que não queria mais brincar só, queria os colegas. Aqui algumas hipóteses interessantes podem ser levantadas. O Complexo de Édipo parece ser um dos conflitos pelos quais a criança está passando e nesse momento de brincadeira podemos supor que um possível desejo foi expresso, mas, isso o levou a se sentir culpado e veio o choro.

Durante as brincadeiras a criança, por vezes, tem atitudes agressivas, de destruição e olha, de forma desconfiada, como que a esperar uma reação minha. Pode-se pensar, neste contexto, na questão da busca de alguém que a imponha limites. A criança que apresenta características agressivas tem dificuldades em controlar a sua raiva e, precisa, portanto, de alguém que a auxilie. Conforme Winnicott (2005) os momentos de explosão da criança, em sala de aula, correspondem a pedidos de ajuda quanto ao controle da destrutividade.

Como o projeto ainda está em andamento tem-se apenas, no momento, algumas hipóteses sobre os conflitos que têm acometido tal criança. Os encontros lúdicos continuarão ao longo do ano. As entrevistas com pais e professora já foram realizadas e o próximo passo será cruzar as informações obtidas por esse meio com os dados obtidos nos encontros lúdicos. Posteriormente, os pais e professores serão orientados acerca das necessidades afetivas infantis, na intenção de se minimizar o quadro agressivo em sala de aula.

\section{CONCLUSÃO}

Conclui-se que as necessidades afetivas das crianças bem como os mecanismos para se trabalhar com esses conflitos de modo a favorecer o desenvolvimento sócio-afetivo das crianças, devem ser compreendidos tanto pelos profissionais da educação em formação quanto os já formados e também pelos pais.

É um privilégio estar participando desse projeto porque acredito na contribuição do mesmo para o exercício de docência e outras funções dentro da área da educação. Espero poder auxiliar os professores e pais a conhecerem mais sobre o processo de desenvolvimento infantil e como podem ajudar essas crianças, e que principalmente, estas possam, por meio dos encontros lúdicos, terem seu sofrimento minimizado e melhoria quanto à agressividade e, conseqüentemente, quanto à aprendizagem. 


\section{REFERÊNCIAS}

WINNICOTT, D. W. A criança e seu mundo. Rio de Janeiro: Imago, 1982.

WINNICOTT, D. W. A família e o desenvolvimento individual. São Paulo: Martins Fontes, 1997.

ABERASTURY, A. A criança e seus jogos. 2.ed. Porto Alegre: Artmed, 1992.

WINNICOTT, D. W. Privação e delinqüência. São Paulo: Martins Fontes, 2005. 